\title{
First Diamino Daphniphyllum Alkaloid, Daphnipaxinin, with An \\ Unprecedented Heterohexacyclic Skeleton from Daphniphyllum
}

\author{
paxianum
}

\begin{abstract}
Sheng-Ping Yang and Jian-Min Yue*
State Key Laboratory of Drug Research, Institute of Materia Medica, Shanghai Institutes for Biological Sciences, Chinese Academy of Sciences, $555 \mathrm{Zu}$ Chong Zhi Road, Zhangjiang Hi-Tech Park, Shanghai, 201203, P. R. China
\end{abstract}

\section{Supporting Information}

Figure S2. Experimental Section S2.

Figure S3. ${ }^{1} \mathrm{H}$ NMR spectrum of daphnipaxinin (1) in $\mathrm{CD}_{3} \mathrm{OD}$.

Figure S4. ${ }^{13} \mathrm{C}$ NMR spectrum of daphnipaxinin (1) in $\mathrm{CD}_{3} \mathrm{OD}$.

Figure S5. DEPT spectrum of daphnipaxinin (1) in $\mathrm{CD}_{3} \mathrm{OD}$.

Figure S6. EIMS spectrum of daphnipaxinin (1).

Figure S7. ESI MS (positive) spectrum of daphnipaxinin (1).

Figure S8. ESI MS (negative) spectrum of daphnipaxinin (1).

Figure S9. ${ }^{1} \mathrm{H}-{ }^{1} \mathrm{H}$ COSY spectrum of daphnipaxinin (1) in $\mathrm{CD}_{3} \mathrm{OD}$.

Figure S10. Expanded ${ }^{1} \mathrm{H}-{ }^{1} \mathrm{H}$ COSY spectrum of daphnipaxinin (1) in $\mathrm{CD}_{3} \mathrm{OD}(\delta$ 2.0-3.6).

Figure S11. Expanded ${ }^{1} \mathrm{H}-{ }^{1} \mathrm{H}$ COSY spectrum of daphnipaxinin (1) in $\mathrm{CD}_{3} \mathrm{OD}(\delta$ 1.35-2.73).

Figure S12. HMQC spectrum of daphnipaxinin (1) in $\mathrm{CD}_{3} \mathrm{OD}$.

Figure S13. HMBC spectrum of daphnipaxinin (1) in $\mathrm{CD}_{3} \mathrm{OD}$.

Figure S14. Expanded HMBC spectrum of daphnipaxinin $(\mathbf{1})$ in $\mathrm{CD}_{3} \mathrm{OD}\left(\delta_{\mathrm{H}} 1.2-2.95\right.$ vs $\left.\delta_{\mathrm{C}} 109.5-210\right)$.

Figure S15. Expanded HMBC spectrum of daphnipaxinin $(\mathbf{1})$ in $\mathrm{CD}_{3} \mathrm{OD}\left(\delta_{\mathrm{H}} 3.05-4.46\right.$ vs $\left.\delta_{\mathrm{C}} 109.5-210\right)$.

Figure S16. NOESY spectrum of daphnipaxinin (1) in $\mathrm{CD}_{3} \mathrm{OD}$.

Figure S17. IR (KBr disc) spectrum of daphnipaxinin (1). 


\section{Experimental Section}

General Procedures: Melting point was recorded on Fisher-Johns melting point apparatus. Optical rotation was determined on a Perkin-Elmer 341 polarimeter. UV and CD spectra were measured on a JASCO J-810 instrument. IR spectra were recorded on a Perkin-Elmer 577 spectrometer. NMR spectra were measured on a Bruker AM-400 spectrometer with TMS as internal standard. EIMS (70 eV) and ESI MS were carried out on a Finnigan MAT 95 mass spectrometer, and a Finnigan LCQ $^{\text {DECA }}$ and a Q-TOF Ultima (for HRESIMS) instruments, respectively. All solvents used were of analytical grade (Shanghai Chemical Plant). Silica gel (200-300 mesh) was used for column chromatography, and pre-coated silica gel $\mathrm{GF}_{254}$ plates (Qingdao Haiyang Chemical Plant) were used for TLC. Sephadex LH-20 (Pharmacia Biotech, Sweden) was also used for column chromatography.

Plant Material: Daphniphyllum paxianum Rosenth was collected from Island Hainan of P. R. China and authenticated by Prof. Su-Hua Shi of Institute of Botany, School of Life science, Zhongshan University of P. R. China. A voucher specimen has been deposited in the Herbarium of Institute of Materia Medica, Shanghai Institute for Biological Sciences, Chinese Academy of Sciences (accession number: DS-2003-4Y-HN). 


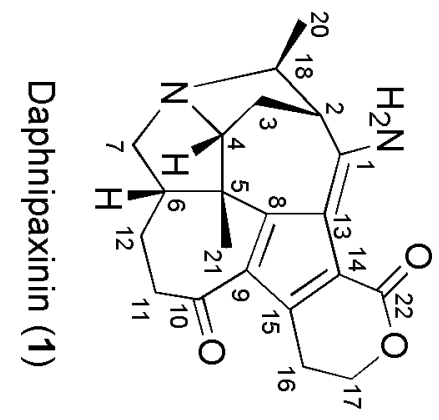

$\omega-$

$$
\frac{0}{1}
$$

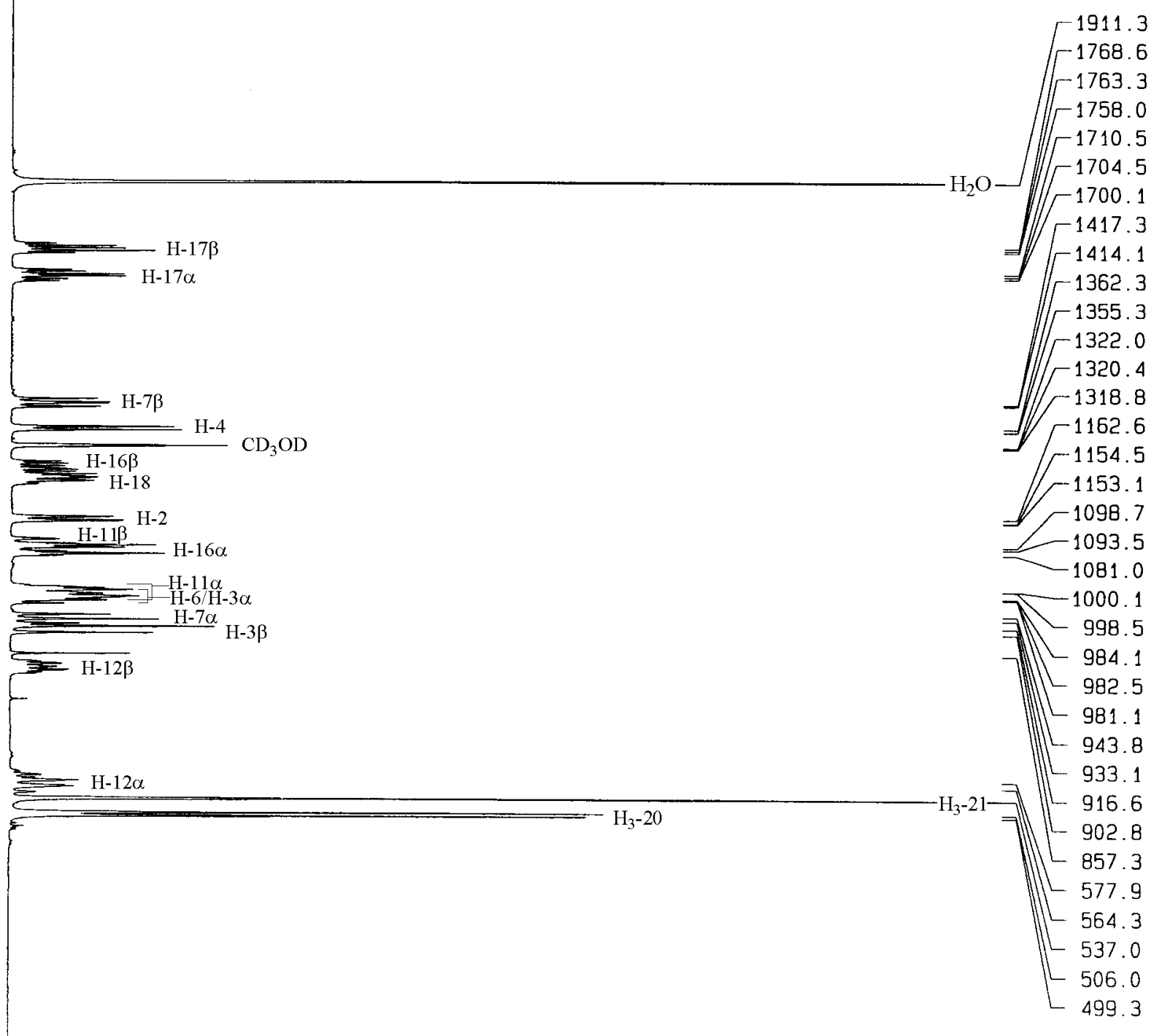


Figure S4. ${ }^{13} \mathrm{C}$ NMR spectrum of daphnipaxinin (1) in $\mathrm{CD}_{3} \mathrm{OD}$

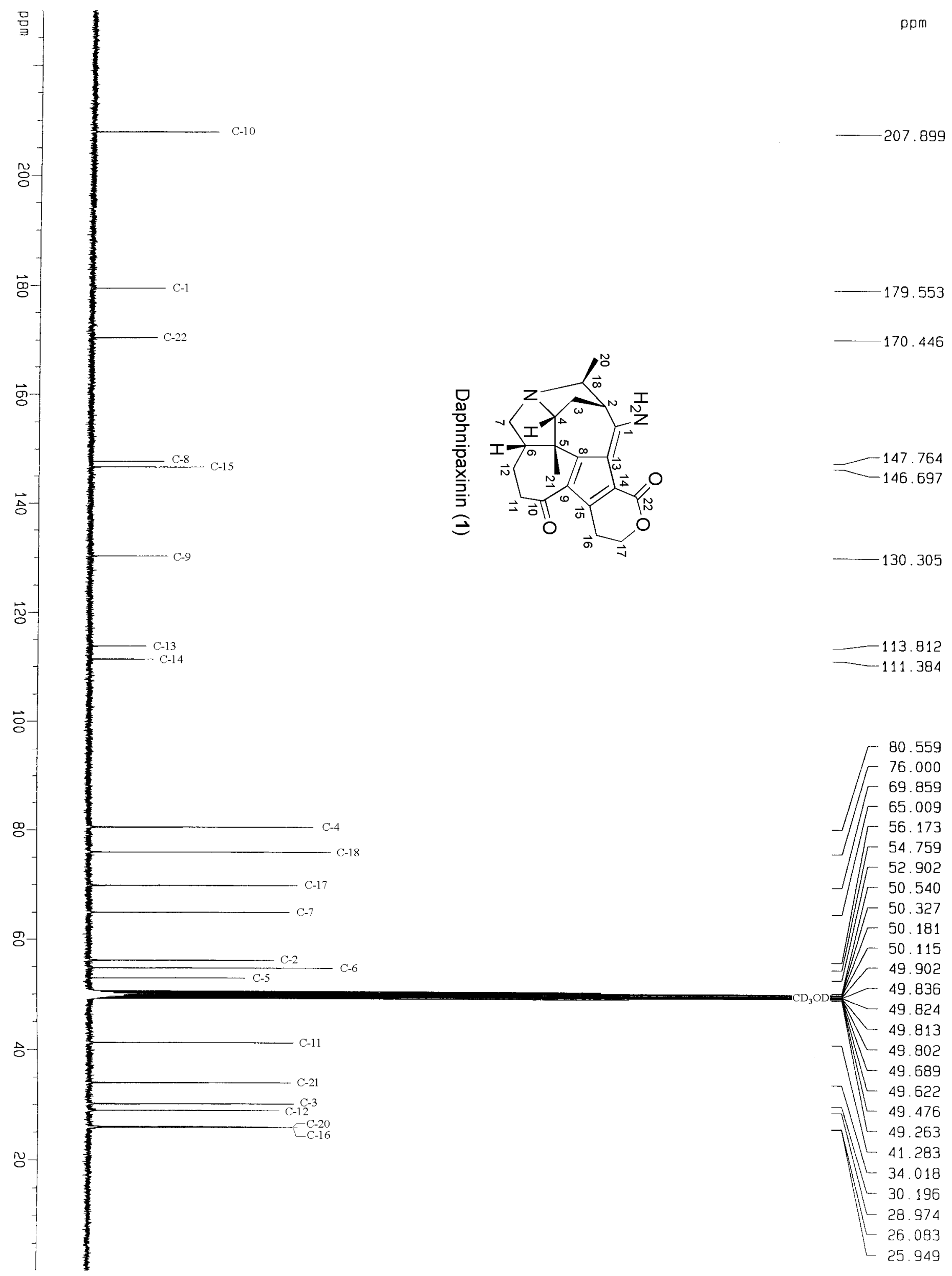


Figure S5. DEPT spectrum of daphnipaxinin (1) in $\mathrm{CD}_{3} \mathrm{OD}$
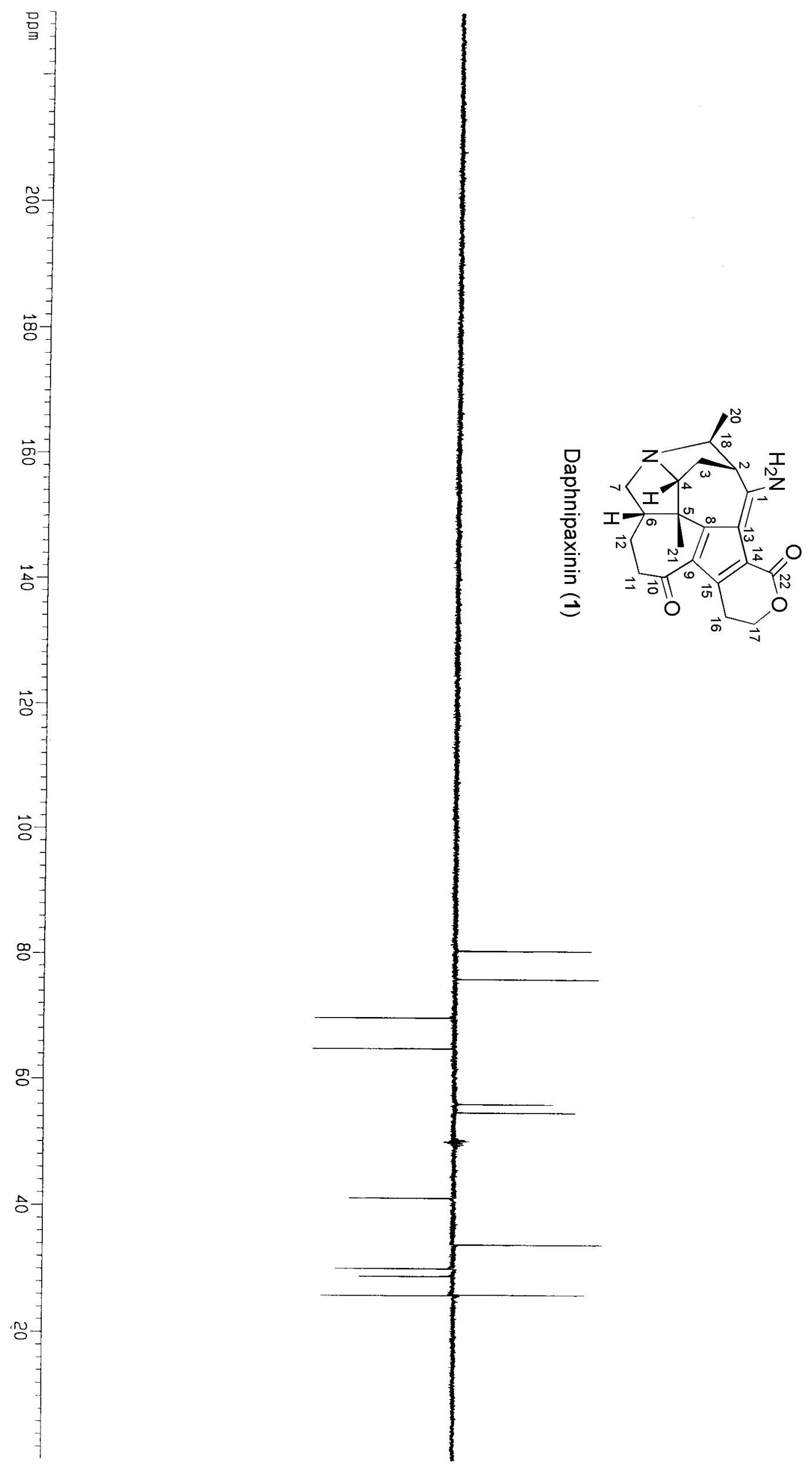
Figure S6. EIMS spectrum of daphnipaxinin (1)

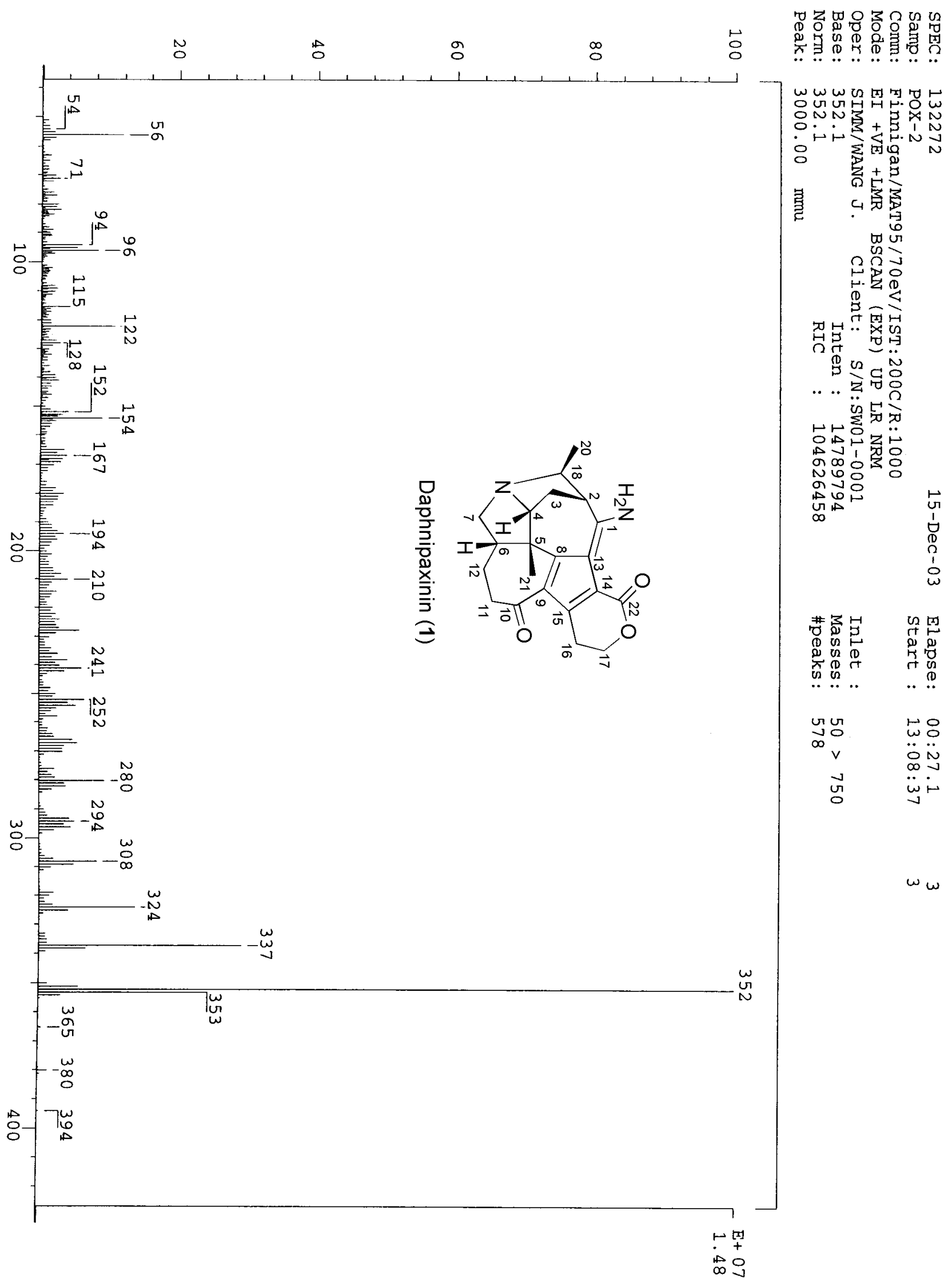


Figure S7. ESI-MS (positive) spectrum of daphnipaxinin (1)

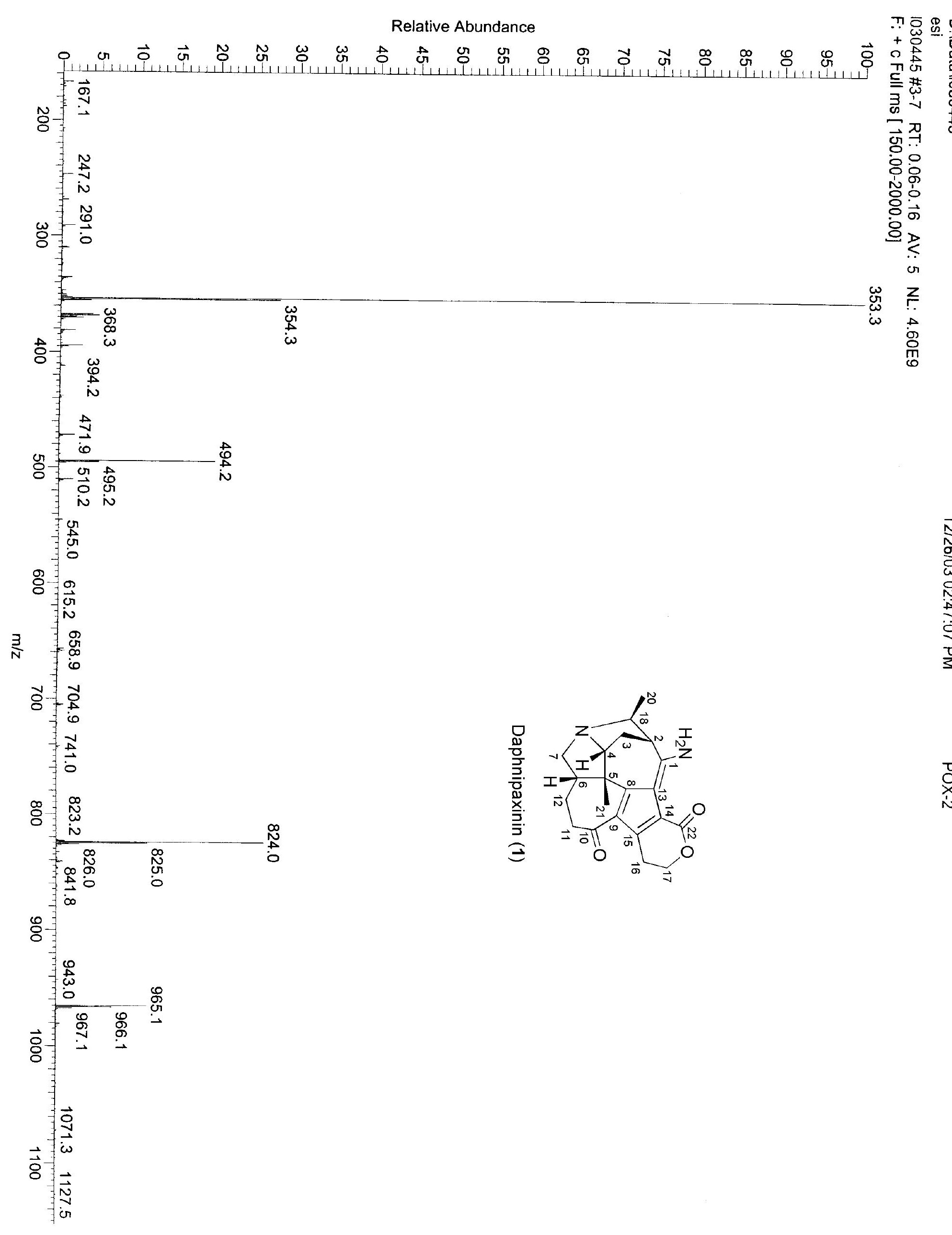


Figure S8. ESI-MS (negative) spectrum of daphnipaxinin (1)

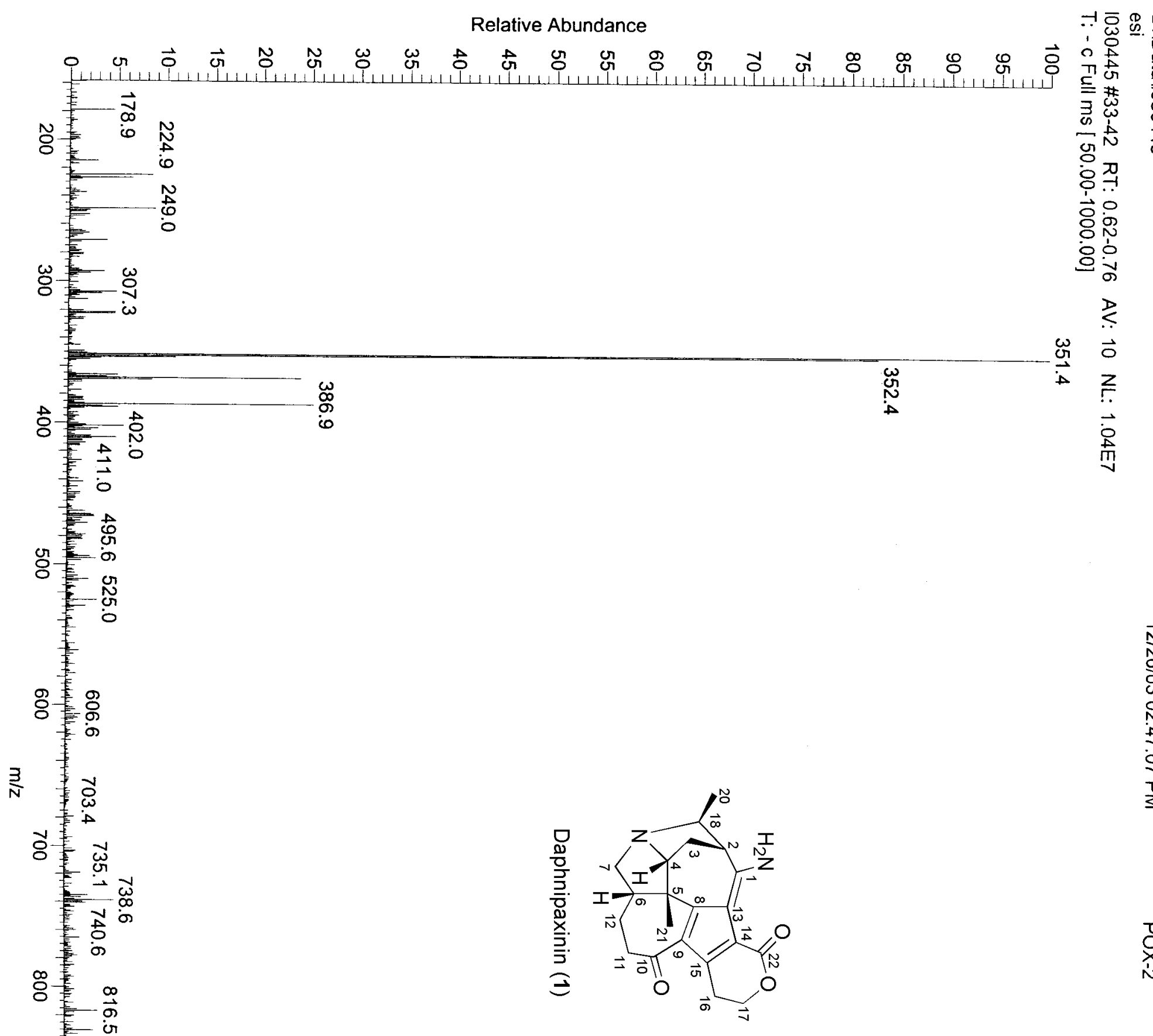


Figure S9. ${ }^{1} \mathrm{H}^{-1} \mathrm{H}$ COSY spectrum of daphnipaxinin (1) in $\mathrm{CD}_{3} \mathrm{OD}$

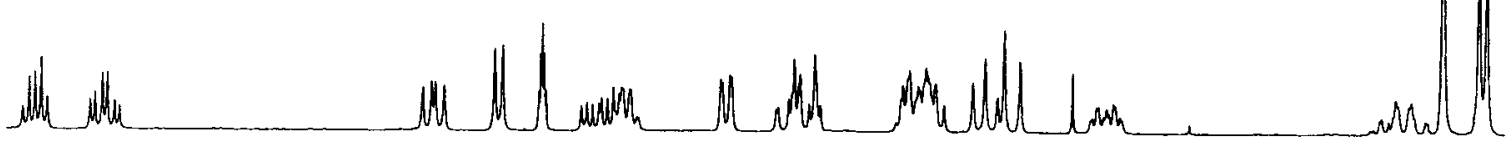
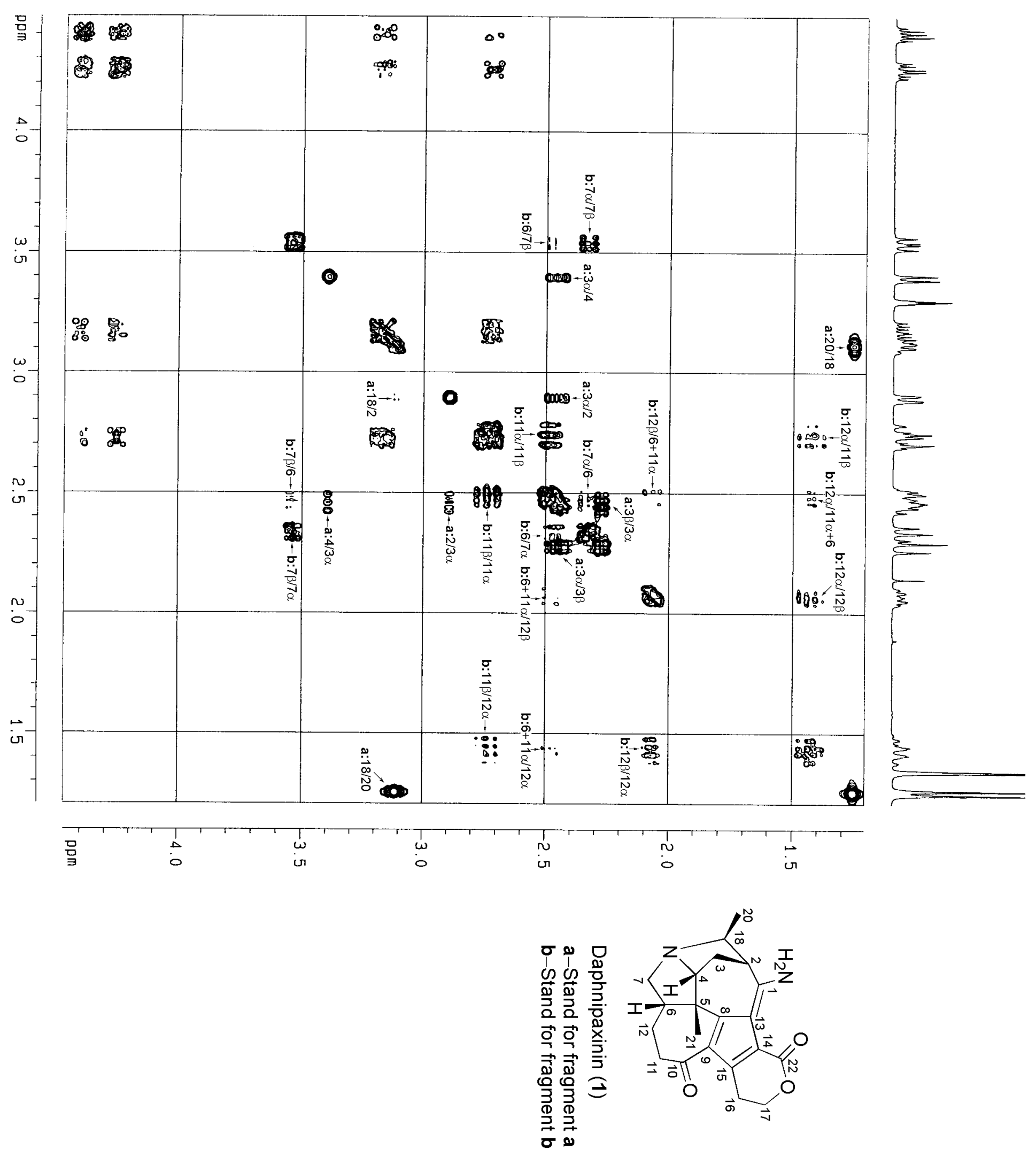
Figure S10. Expanded ${ }^{1} \mathrm{H}-{ }^{1} \mathrm{H}$ COSY spectrum of daphnipaxinin (1) in $\mathrm{CD}_{3} \mathrm{OD}(\delta$ 2.0-3.6).

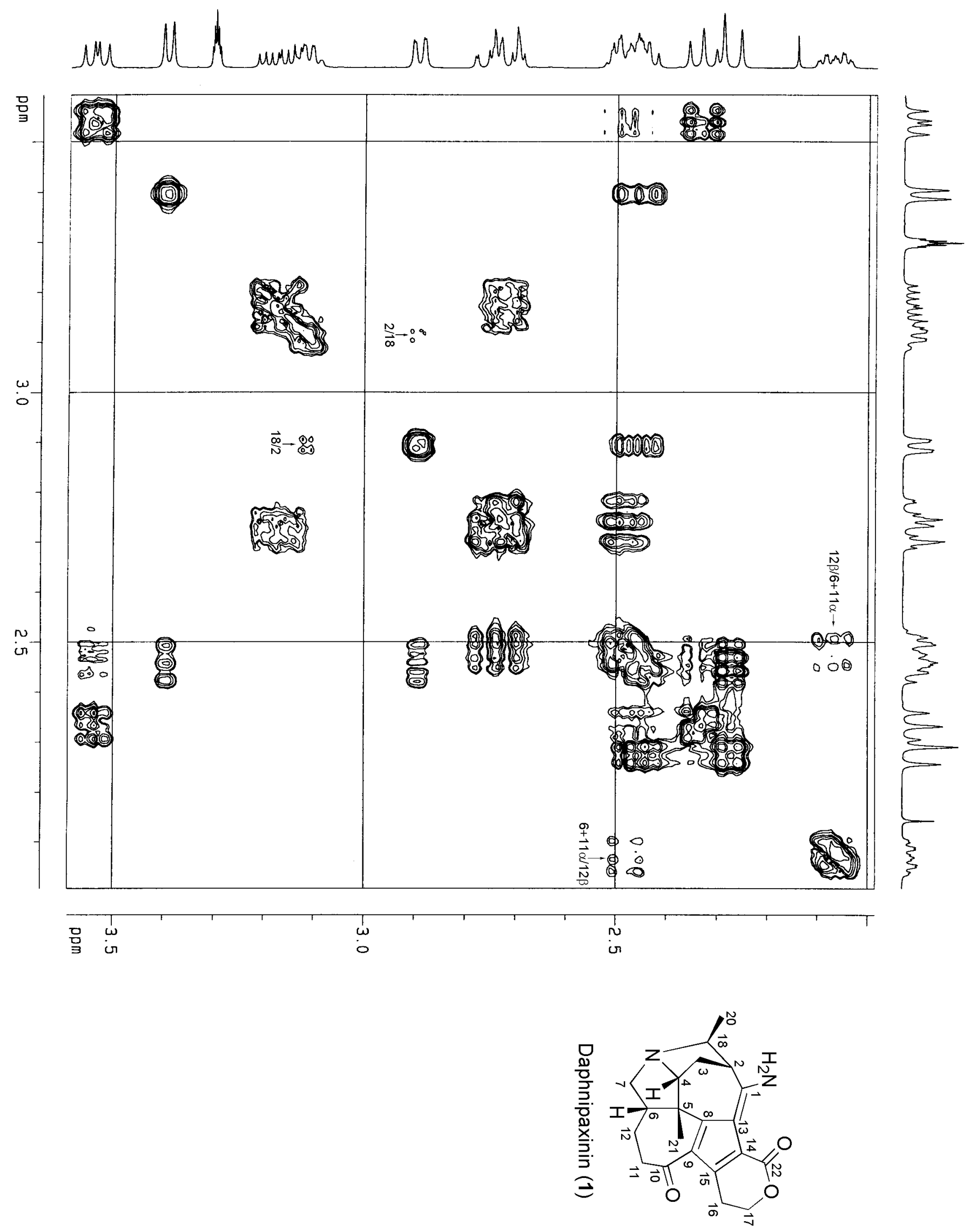


Figure S11. Expanded ${ }^{1} \mathrm{H}_{-}{ }^{1} \mathrm{H}$ COSY spectrum of daphnipaxinin (1) in $\mathrm{CD}_{3} \mathrm{OD}(\delta$ 1.35-2.73).

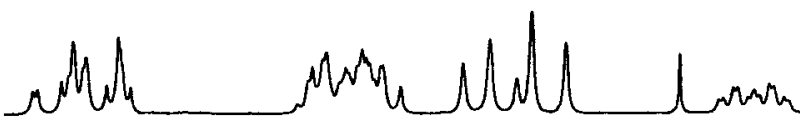
MU

总
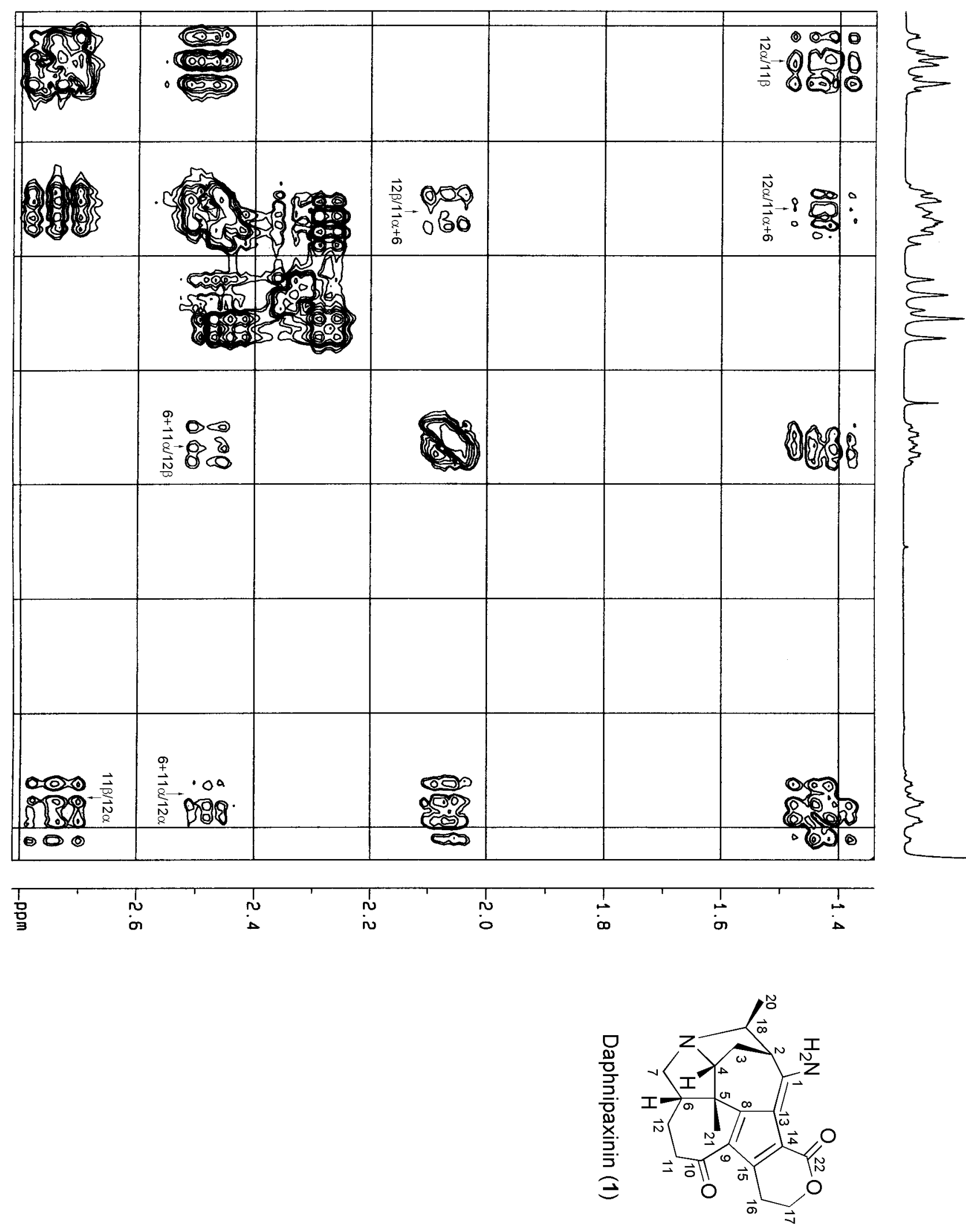
Figure S12. HMQC spectrum of daphnipaxinin (1) in $\mathrm{CD}_{3} \mathrm{OD}$

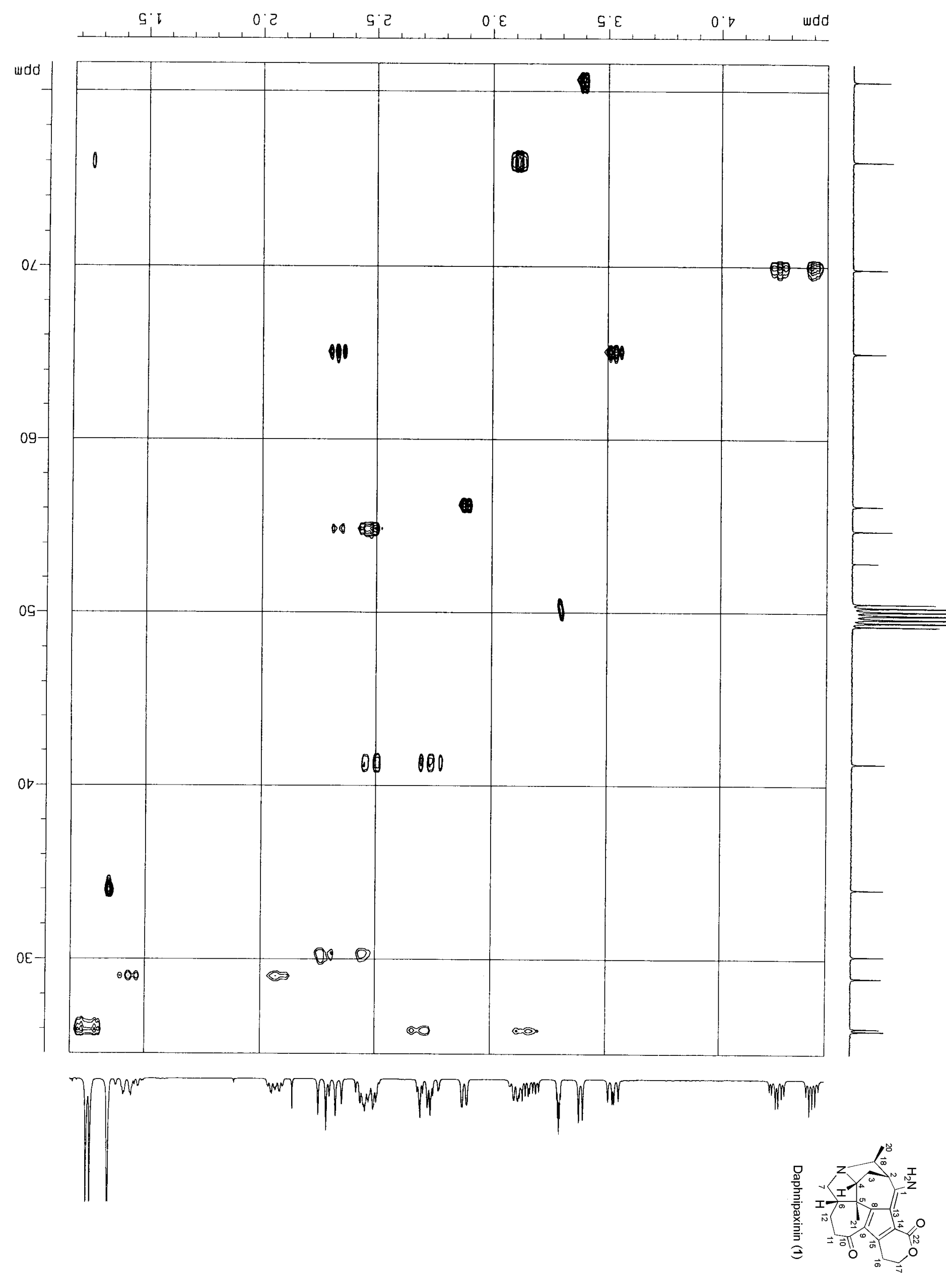


Figure S13. HMBC spectrum of daphnipaxinin (1) in $\mathrm{CD}_{3} \mathrm{OD}$

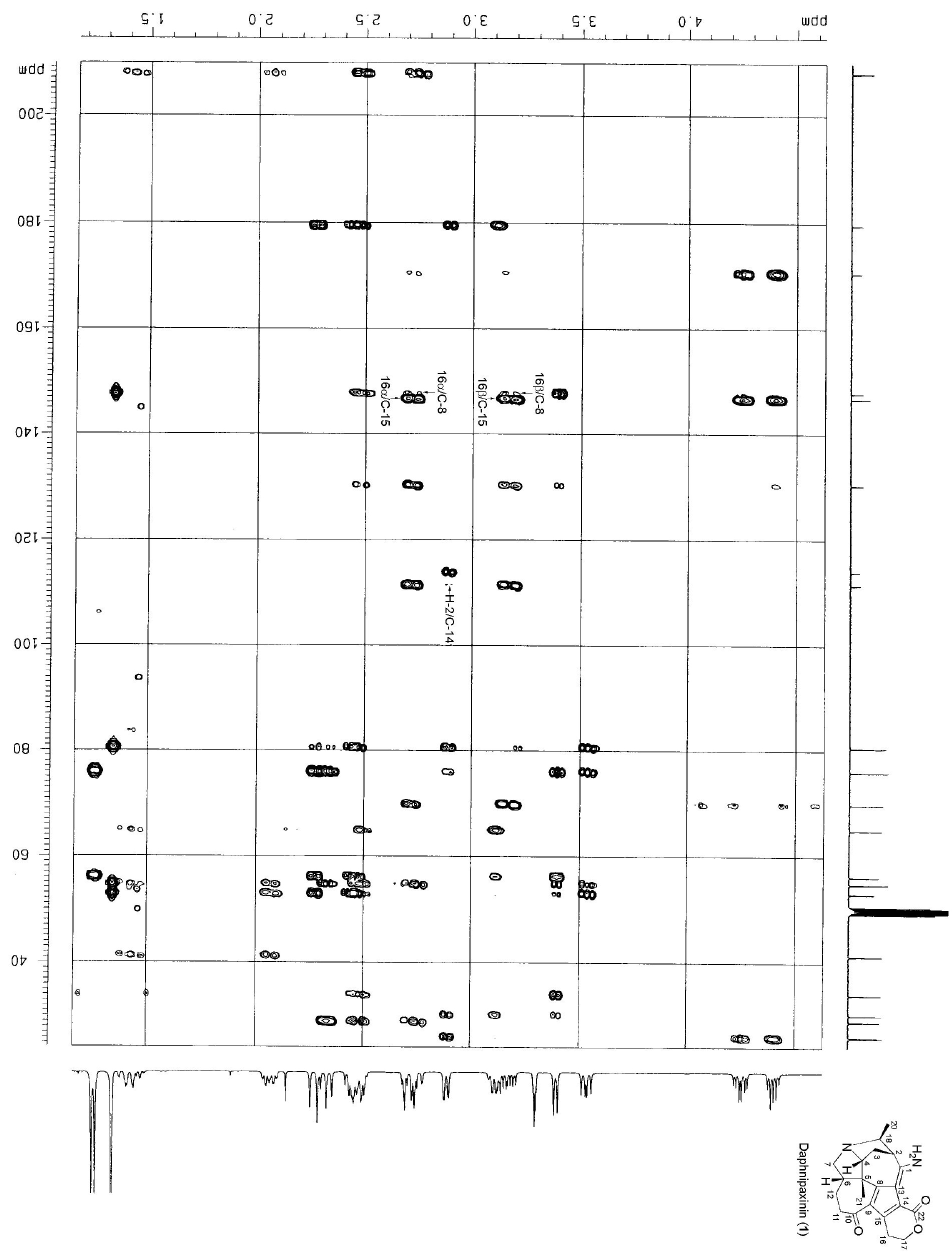


Figure S14. Expanded HMBC spectrum of daphnipaxinin (1) in $\mathrm{CD}_{3} \mathrm{OD}$.

$\left(\delta_{\mathrm{H}} 1.2-2.95\right.$ vs $\left.\delta_{\mathrm{C}} 109.5-210\right)$
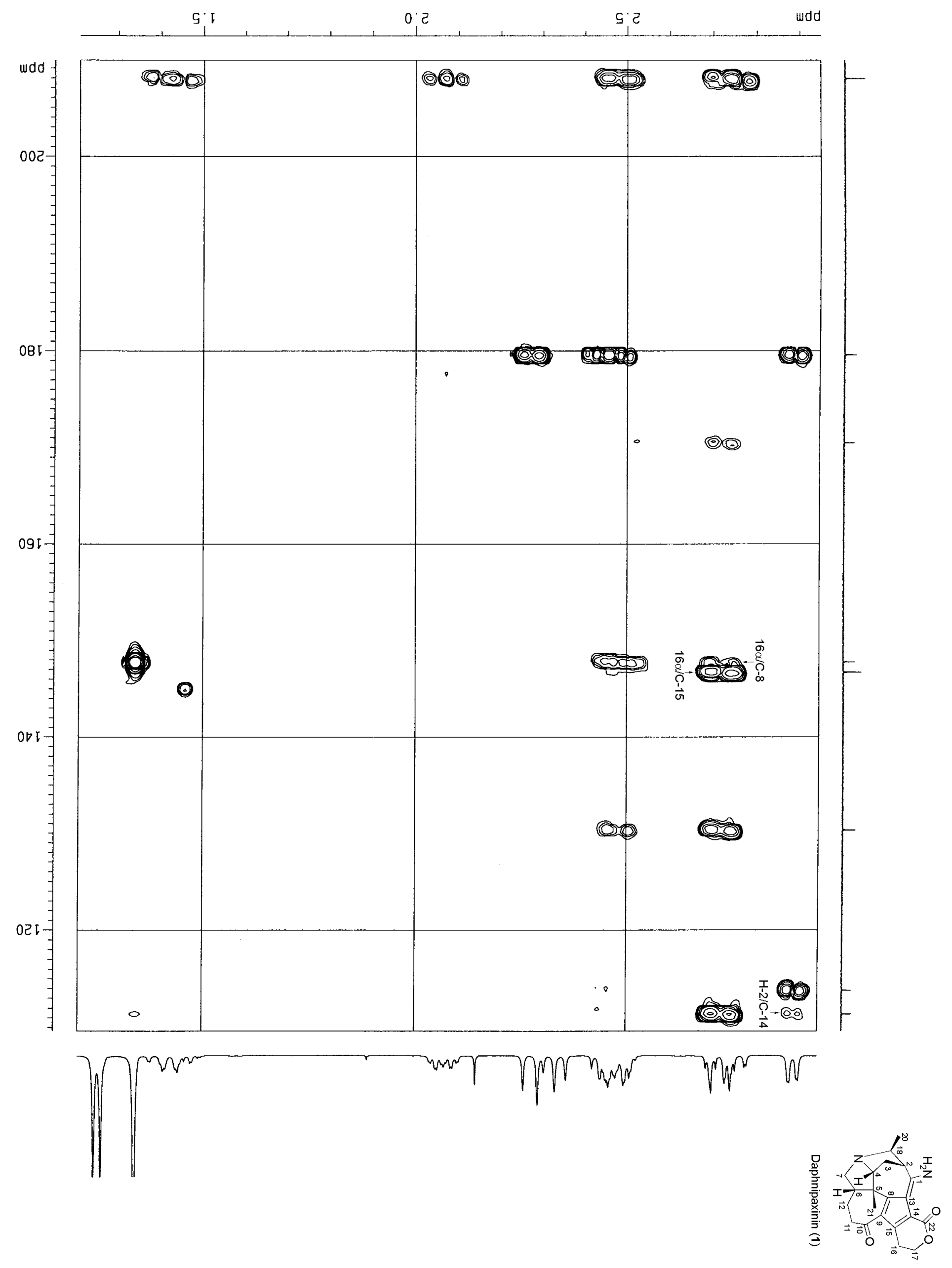
Figure S15. Expanded HMBC spectrum of daphnipaxinin (1) in $\mathrm{CD}_{3} \mathrm{OD}$. $\left(\delta_{\mathrm{H}} 3.05-4.46\right.$ vs $\left.\delta_{\mathrm{C}} 109.5-210\right)$

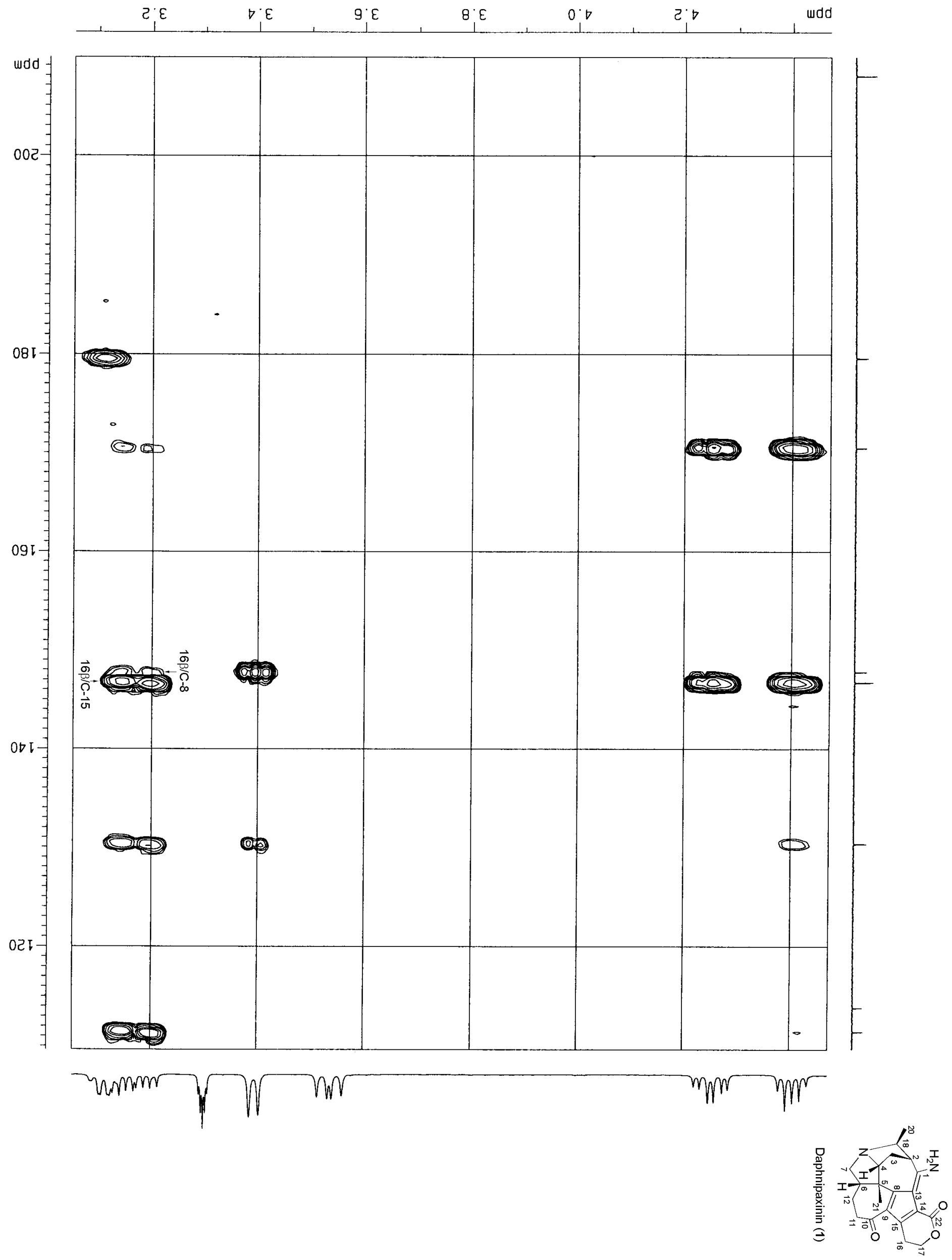


Figure S16. NOESY spectrum of daphnipaxinin (1) in $\mathrm{CD}_{3} \mathrm{OD}$

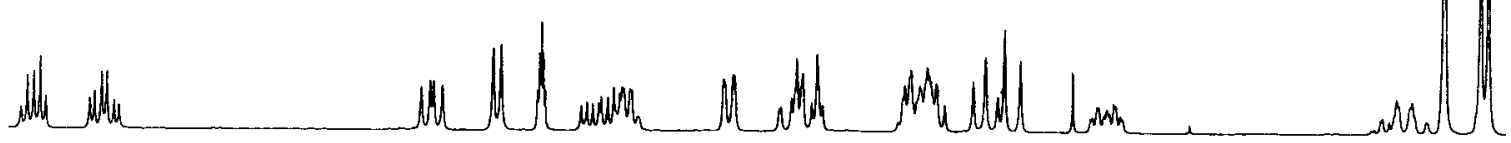
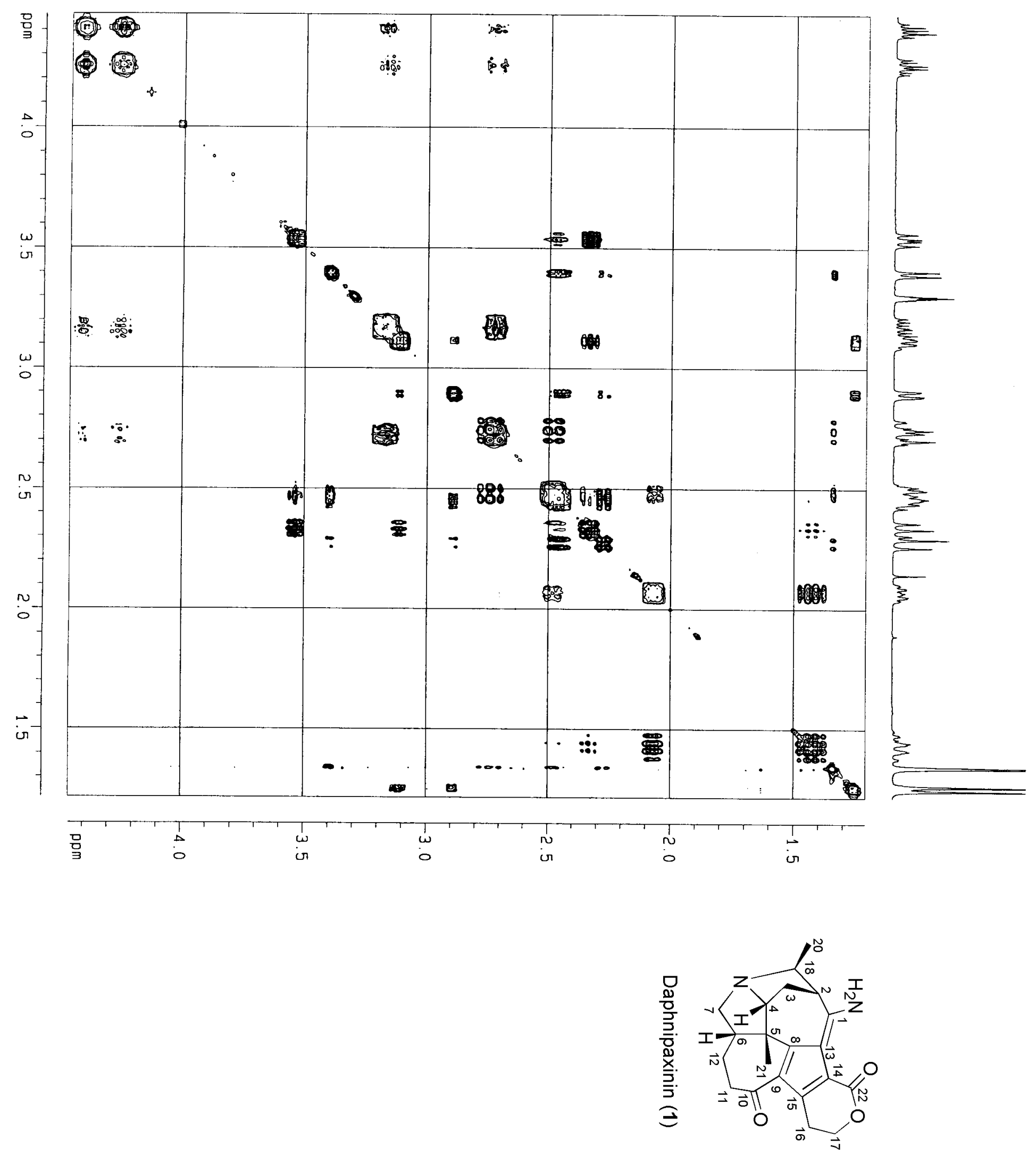
Figure S17. IR (KBr) spectrum of daphnipaxinin (1)

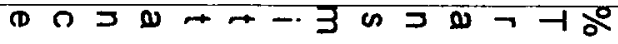

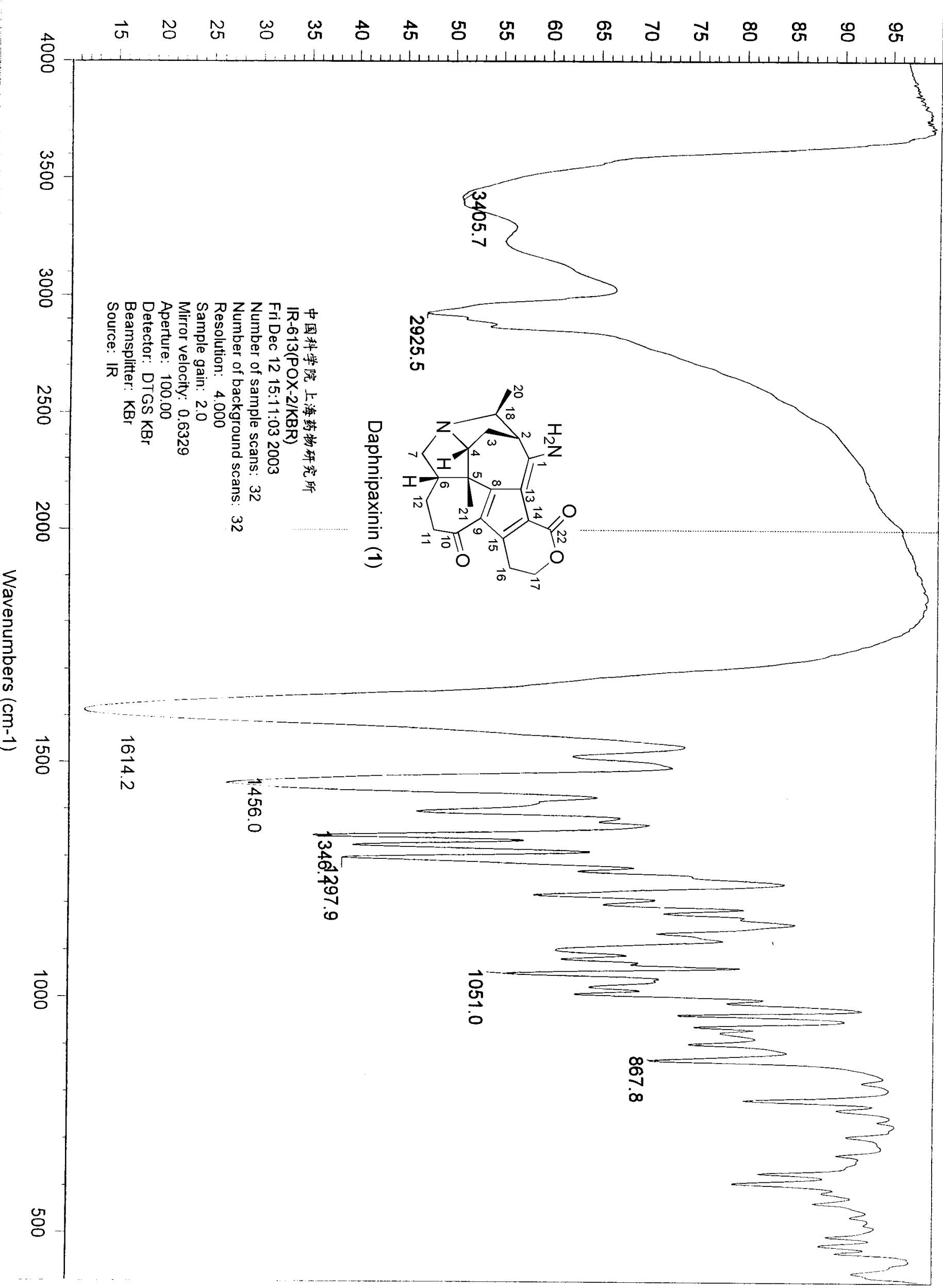

